\title{
Identification of 'Defects' in Epoxy Matrix Composites and Carbon Fiber by Ultrasound. Interaction of the Ultrasonic Beam with the Material
}

\author{
Gaston Sanglier ${ }^{1}$, Eduardo J. Lopez ${ }^{1}$, Sonia Cesteros ${ }^{1} \&$ Roberto A. Gonzalez ${ }^{1}$ \\ ${ }^{1}$ Architecture and Design Department, Engineering Area, Escuela Politécnica Superior, Universidad CEU San \\ Pablo, Montepríncipe Campus, 28668, Boadilla del Monte, Madrid, Spain \\ Correspondence: Gaston Sanglier, Engineering Area, Escuela Politécnica Superior, Universidad CEU San Pablo, \\ Montepríncipe Campus, 28668, Boadilla del Monte, Madrid, Spain.
}

Received: September 2, 2020

Accepted: October 28, 2020

Online Published: December 22, 2020

doi:10.5539/mas.v15n1p32

URL: https://doi.org/10.5539/mas.v15n1p32

\begin{abstract}
Non-Destructive Testing (NDT) methods, and especially, ultrasounds have gone from being a mere laboratory curiosity to an indispensable tool in the industry as a primary means of determining the level of quality achieved in its products (ASM, 1989; Barbero, 1999).

This study will identify and apply the main physical phenomena of interaction of an ultrasonic wave in a composite material, to see if through this type of waves, you can detect defects of the type of porosity or delaminations in these materials. The percentages of reflected and transmitted waves in real cases of defects in the composite material will also be studied. It will be shown if the frequencies and intensities of the waves are adequate to find this type of defects or imperfections in the material.

The theoretical study of the ultrasonic wave seeks to help researchers in the development of equipment that uses the methodology of immersion ultrasound for the inspection of materials in the search for 'defects' and to understand the physics of the test.
\end{abstract}

Keywords: ultrasound, carbon fiber, epoxy matrix, porosity, delamination, NDT techniques

\section{Introduction}

In the last decades the operating requirements have increased, while at the same time trying to reduce the weight of the structures and mechanical components used for industrial purposes. This has led to the need to use advanced materials that have high mechanical properties along with a decrease in weight (Inasmet, 1998). The use of fiber reinforced polymeric matrix composites has replaced in many cases conventional materials (steel, plastic, aluminum, concrete, etc.). These materials have been used preferably in the aeronautical and space industry for the manufacture of floor panels, spoilers, rudders, depth rudders, interior and exterior ailerons, space shuttles, satellites, etc. where they have had a greater development because they are structures that require high values of resistance and specific rigidity, and in which the weight factor entails a great decrease in the cost (Sanglier et al., 2003; Ramírez \& Col, 1982; Wróbel \& Wierzbicki, 2005; Ramírez López et al., 1996).

Fiber-reinforced composite materials are also used in other sectors such as construction, wind turbines, marine, elite sports, automotive and other sectors such as medical and military (ImieliÉska et al., 2004; Rojek, Stabik, \& Wróbel, 2005; Ochelski, 2004).

These composite materials are characterized by high rigidity and mechanical resistance, high fatigue resistance, corrosion resistance, low weight and the possibility of selecting the appropriate orientation of the sheets for each specific application. Their low thermal conductivity and high dimensional stability give these materials a very interesting alternative in applications subject to low temperature conditions.

The structural components of this type are made up of plate and/or beam type elements, which are subjected to loads perpendicular to their plane that originate a state of work in bending in which tensile and compressive stresses appear (Padmanabhan \& Kishore, 1995; Potel et al., 1998; Scarponi \& Briotti, 2000; Vaccaro \& Akers, 1996). For example, these tensile states can appear in the aerodynamic loads exerted on the wings of an aircraft. 
However, another aspect of great importance and where this study is going to be centered is the identification of defects understood as porosity, delamination or accumulation of material (fiber cuts, resin, fiber breakage, etc.) that can cause the failure of the material in case of receiving impact loads on the structure of composite material. It has been observed experimentally that the delaminations produced by this type of impact considerably reduce the resistance to compression (Cantwell et al., 1986; Gray et al., 1995; Baker, Jones, \& Callinan, 1985; Bishop, 1985).

For all these reasons, it is necessary to know how to identify, using some NDT (Non-Destructive Testing) technique, in this case the ultrasounds, those possible defects attending to the study of the physical phenomena of interaction of a wave with the composite material and to be able to calculate and interpret the percentage of reflected and transmitted wave in a determined imperfection or defect.

\section{Methods}

To carry out the study, several panels have been manufactured (one of reference, another with medium porority and a third with delaminations) of composite material based on a modified epoxy matrix 8552 together with high resistance carbon fiber AS4 preimpregnated in the form of unidirectional tape with a curing temperature of $180^{\circ} \mathrm{C}$ manufactured in an autoclave, curing pressure 6 bars, volumetric fiber content of $62 \%$ and nominal thickness of the cured layer of $0.13 \mathrm{~mm}$ with a fiber weight per area of $145 \mathrm{gr} / \mathrm{m}^{2}$. The size of the panels was $34 \mathrm{~cm}$ high by $29 \mathrm{~cm}$ wide.

Sixteen layers were used, overlapped in a unidirectional way (direction of the fibre $0^{\circ}$ ) with a final panel thickness (test piece) of $3 \mathrm{~mm}$ after the curing phase. Each layer has a thickness of $0.1875 \mathrm{~mm}$, then the porosity was caused in the fourth layer (at $0.75 \mathrm{~mm}$ from the surface) and the delaminations were made in the eighth layer (at $1.5 \mathrm{~mm}$ from the surface, in the central part of the test piece).

Below are some images of the specimens used in the test. The specimen with the letter $\mathrm{R}$ in the lower central part corresponds to the reference specimen (well made with no defects), the specimen P1 on the right corresponds to the specimen with medium porosity, and finally, the specimen P2 on the left corresponds to the delaminations.

Attached are some images taken by ultrasound using total immersion transmission with $1 \mathrm{MHz}$ frequency of the three types of panels analyzed. The image is a very powerful instrument that allows to integrate a great amount of information to capture it in a single glance. It makes it possible to easily compare adjacent areas with small differences in attenuation or travel time, and digital support techniques allow the technician to easily optimize observation conditions (Huang et al., 1998; Mouritz, Townsed, \& Shah Khan, 2000; Kino, 1979). A test of this type is intrinsically insensitive and the signal detected is usually quite affected by noise or instability that causes its amplitude to oscillate. However, despite the low sensitivity there is a high defect capacity.

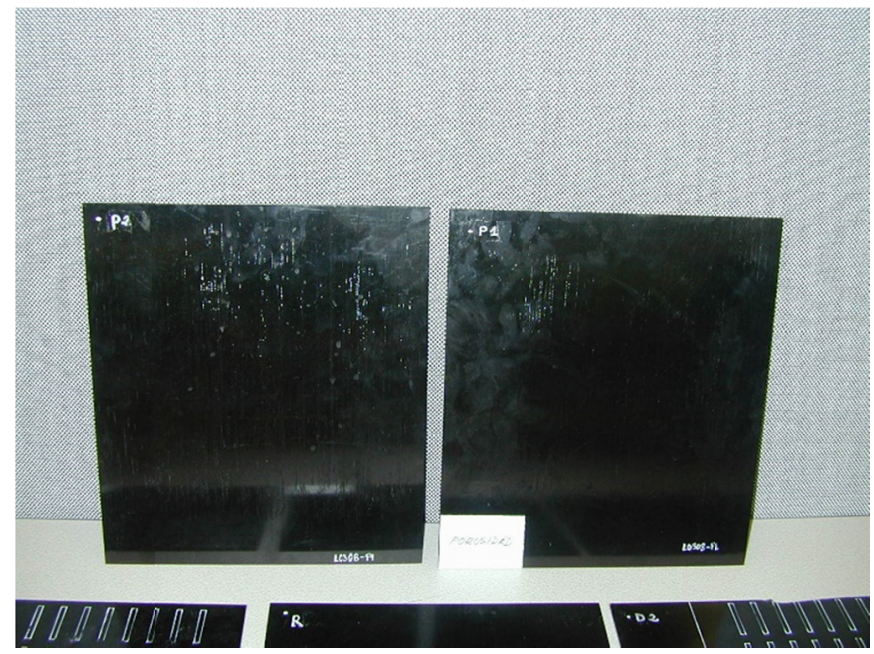

Figure 1. Different types of specimens in the ultrasonic test 
Attached are some images taken by ultrasound using the $1 \mathrm{MHz}$ total immersion transmission of the three types of specimens.
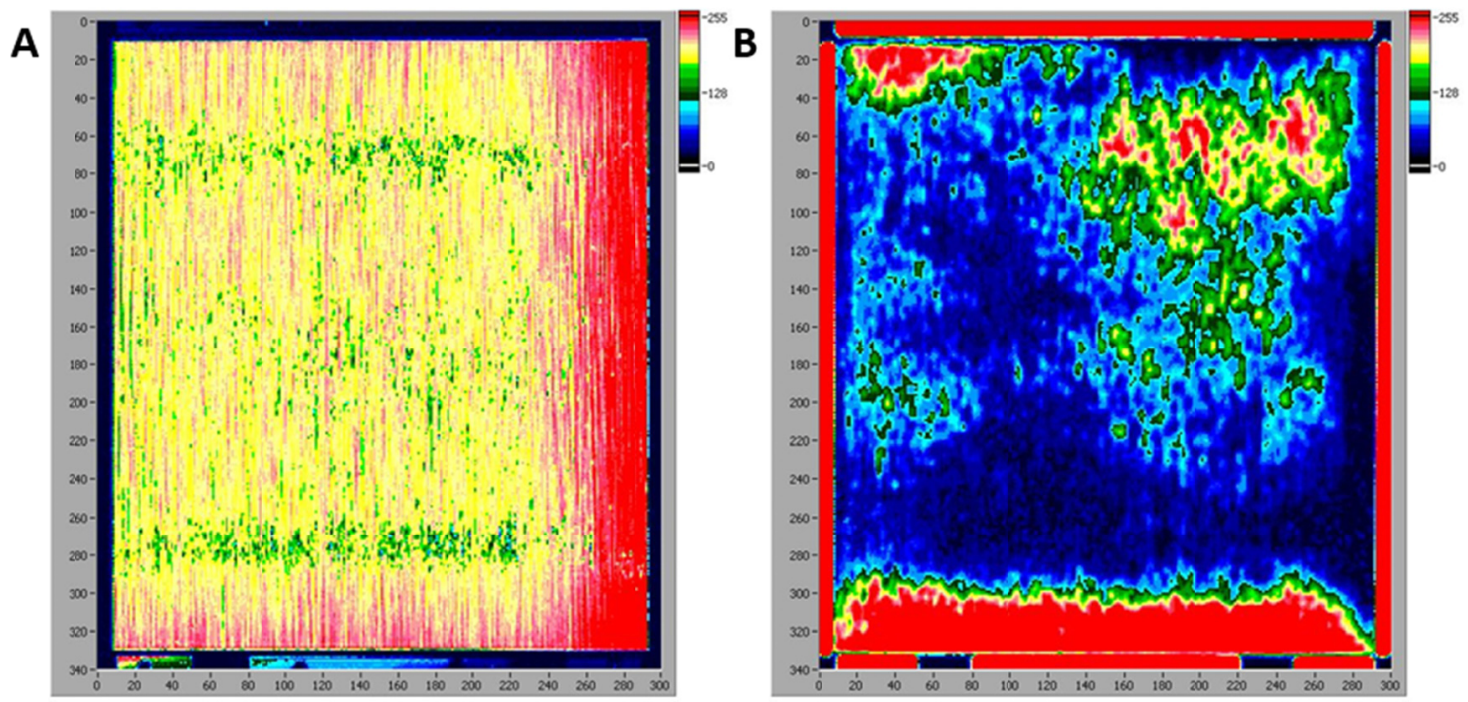

Figure 2. Reference test tube on the left (A) and P1 test tube with medium porosity on the right (B) of epoxy matrix reinforced with carbon fiber

Figure 2 (left) shows an ultrasonic inspection using immersion transmission of the reference specimen (without defects) of the material under study. It is observed the unidirectionality of the fiber at $0^{\circ}$ along the whole sample. In figure 2 (right) it is observed an ultrasonic inspection using immersion transmission of the test tube P1 where areas with medium porosity have been generated in the fourth layer of the test tube or sample. Especially the lower zone in red marks this circumstance, in addition to the upper central zone.

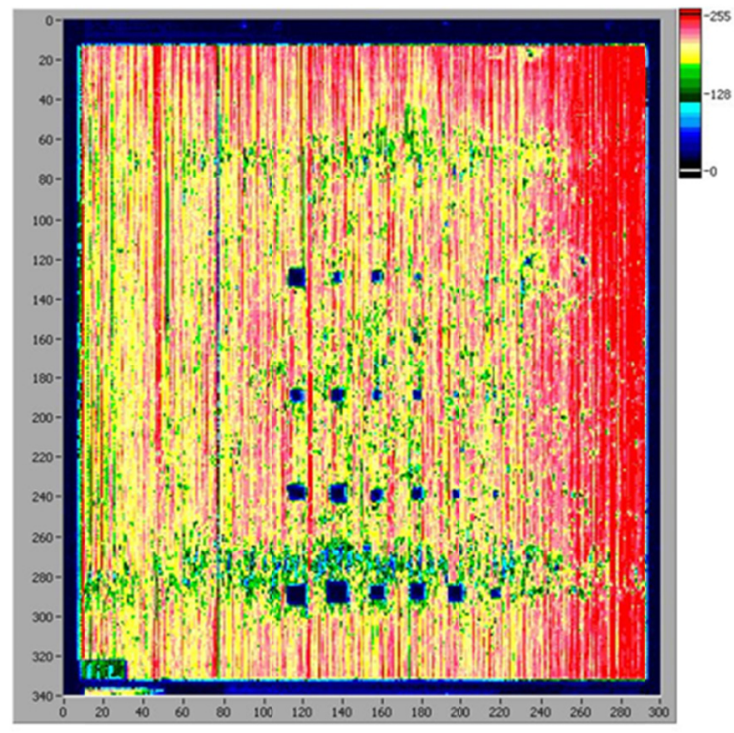

Figure 3. P2 test tube with delamination zones in the sample

In figure 3, an ultrasonic inspection using immersion transmission of the P2 specimen is shown where different defects have been generated. A kind of dark squares clearly aligned in four rows appear. These defects, delaminations caused by Teflon bags, application of release agents, resin sticking, fiber cuttings, etc. of different sizes $(3 \times 3 \mathrm{~mm}, 5 \times 5 \mathrm{~mm}, 7.5 \times 7.5 \mathrm{~mm}, 9 \times 5 \mathrm{~mm} 10 \times 10 \mathrm{~mm})$ placed between layers have been placed in layer 8 of the test piece. 


\subsection{Theoretical Foundations and Concepts}

Ultrasound measurements have been made by immersion testing of the specimen (Silk, 1982; Huang et al., 2000; Nesvijski, 2000; Dunegan \& Tetelman, 1971), in this case the specimen and the probe are immersed (76 mm water layer) in the coupling fluid, which is almost always water with the necessary additives to prevent corrosion damage. The stability of the output signal is directly related to the quality of the water jet, and more specifically to the absence of turbulence. The design of the probe nozzle is critical as it can cause disturbances. The separation between stylus nozzle and sample is $20 \mathrm{~mm}$. Using this technique, panel or probe inspection is much faster and can be done automatically (Maskov et al., 2000; Marsh, 2002; Vadecantos, Miguel, \& Gallego, 1995).
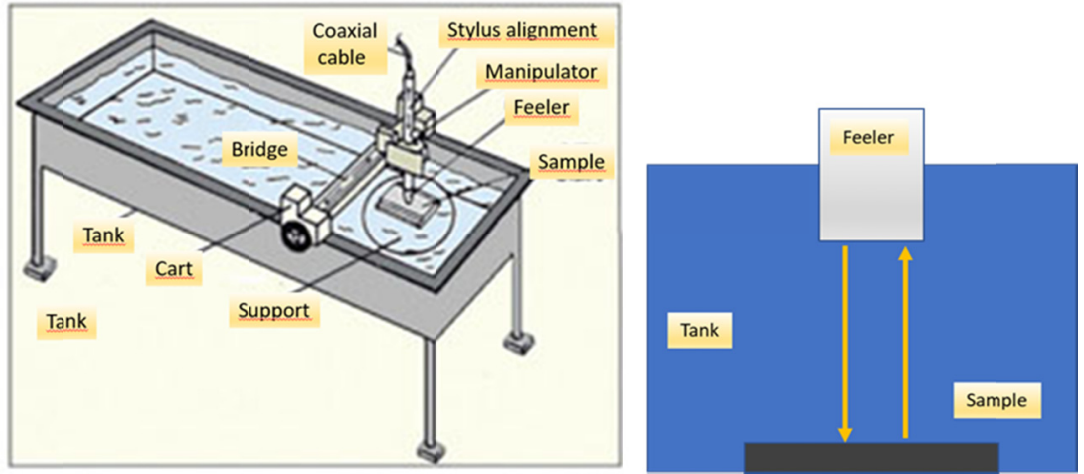

Figure 4. Left: water tank immersion system. Right: Measured on the part by immersion transmission

It will be taken into account that when an ultrasonic beam passes through a material, certain physical phenomena will occur that will be necessary to know for a better interpretation of the results. When we speak of ultrasonic wave we refer to frequencies higher than $20 \mathrm{KH}$, within this band we can speak of nearby ultrasound (frequency between 20 and $100 \mathrm{KH}$ ), band from 0.2 to $25 \mathrm{MHz}$ and frequencies above $100 \mathrm{MHz}$ which is the field of acoustic microscopy. These ultrasonic waves can propagate through any material medium, where there are atoms and molecules capable of vibrating. However, these waves are attenuated by all materials according to different absorption and dispersion phenomena, so not all media are suitable for transmitting ultrasound (Ramirez Lopez et al., 1996; Hervfeld \& Litovitis, 1959).

Next, some important parameters will be defined for the study to be carried out (Alonso \& Finn, 1987; Pollock, 1987; Kapranos \& Priestner, 1987; Harvey, 1963; Mundry, 1968).

Wave frequency (f): is the number of oscillations of a particle per second. Within the same wave, it is the same for all particles and is identical to the frequency of the generator, which can be chosen arbitrarily.

Acoustic velocity $(\mathrm{C})$ : is the propagation velocity of the wave for a given condition, for example, in a compression zone. This velocity is a characteristic of the material and, in general, is constant for a given material, at any frequency and any wavelength. However, this is not strictly accurate, since such speed depends, especially in liquids and gases, on pressure, temperature and other parameters. However, in many solid materials, such as metals, this influence can be neglected. For this reason, this speed can be taken approximately as a constant of the material, a very useful condition for ultrasonic testing. The acoustic velocity for a longitudinal wave is given by the formula:

$$
C_{L}=\sqrt{\frac{E \cdot(1-\mu)}{\rho \cdot(1+\mu) \cdot(1-2 \mu)}} \quad(\mathrm{m} / \mathrm{s})
$$

where $\mathrm{E}$ is the modulus of elasticity $\left(\mathrm{N} / \mathrm{m}^{2}\right), \mu$ is the Poisson coefficient (dimensionless) quotient between lateral and axial deformations and $\rho$ is the density of the material $\left(\mathrm{Kg} / \mathrm{m}^{3}\right)$.

Acoustic impedance (Z): not all materials will behave the same way when they are crossed by an ultrasonic wave. The resistance that the materials oppose to the passage of the ultrasonic wave is what is known as acoustic impedance, impedance of the acoustic wave or specific acoustic impedance. It is a resistance that opposes the vibration of the wave. If a medium has a low impedance, its mass elements will vibrate at high speed, with only a small change in sound pressure; that is, the medium will offer little resistance to the elastic deformations caused by the wave. If, on the contrary, the impedance is high, the mass elements will vibrate slowly, even if the acoustic pressure is high, since the medium offers great resistance to elastic deformations. Experimentally, it can be calculated through the formula:

$$
Z=\rho . C_{L} \quad\left(\mathrm{Kg} / \mathrm{m}^{2} . \mathrm{s}\right)
$$


which indicates that the acoustic impedance is a constant of the material. Materials with a high impedance are called "acoustically hard" ( $\mathrm{Kg} / \mathrm{m}^{2} . \mathrm{s}$ ). Impedance in solid bodies is generally higher than in liquids and, in these, higher than in gases.

On the other hand, if a flat acoustic wave falls perpendicularly on a flat and soft surface that separates two different media, a part of the energy of the wave is reflected and returns in the same direction of the incident, another part propagates in the second medium maintaining its direction and sense. If Ii is the intensity of the incident wave, Ir the reflected one, It the transmitted one and $\mathrm{Z}_{1}$ and $\mathrm{Z}_{2}$ the respective acoustic impedances of the materials, this is graphically exposed as follows:

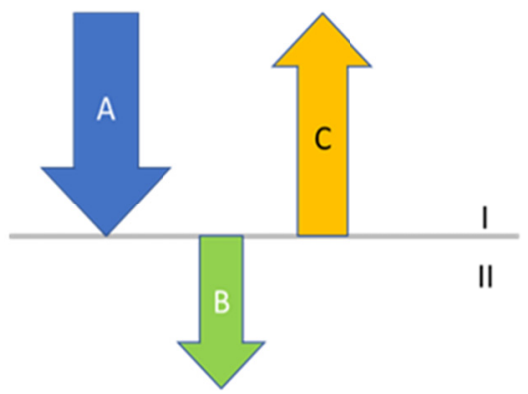

Figure 5. Perpendicular incidence of the sound wave on a flat surface

It can be seen from figure 5 above, that $\mathrm{A}$ is the incident energy, $\mathrm{B}$ is the energy transmitted from medium I to medium II and $\mathrm{C}$ is the energy reflected on the boundary surface $\mathrm{I}$, so that $\mathrm{A}=\mathrm{B}+\mathrm{C}$.

We call $\mathrm{R}$ the reflection coefficient and $\mathrm{T}$ the transmission coefficient that are given by:

$$
\begin{aligned}
R & =\frac{I_{r}}{I_{i}} ; \\
T & =\frac{I_{t}}{I_{i}}
\end{aligned}
$$

Both are dimensionless coefficients that express the percentage of reflected and transmitted intensity respectively in relation to the incident intensity.

The energy balance expressed in intensities remains: $I_{i}=I_{r}+I_{t}$ and therefore can be put: $\mathrm{R}+\mathrm{T}=1$. From the theory of propagation of acoustic waves it is obtained that:

$$
\begin{aligned}
R & =\frac{\left(Z_{2}-Z_{1}\right)^{2}}{\left(Z_{1}+Z_{2}\right)^{2}} ; \\
T & =\frac{4 Z_{1} Z_{2}}{\left(Z_{1}+Z_{2}\right)^{2}}
\end{aligned}
$$

It can be deduced that from the point of view of the acoustic intensities, it is indifferent the side of the limit surface on which the wave affects since the values of $R$ and $T$ do not change when exchanged between $Z_{1}$ and $Z_{2}$. As the specific acoustic energy is given by:

$$
E_{e^{\prime}}=\frac{1}{2} \rho V^{2}=\frac{1}{2} \rho w^{2} A^{2}=\frac{P^{2}}{2 \rho C^{2}}=\frac{P^{2}}{2 Z C}\left(W / m^{2}\right)
$$

and the sound intensity by the following formula:

$$
I=\frac{1}{2} \rho C V^{2}=\frac{1}{2} Z V^{2}=\frac{1}{2} Z w^{2} A^{2}=\frac{1}{2} \frac{P^{2}}{Z}\left(\mathbb{W} / m^{2}\right)
$$

where $\mathrm{w}$ is the angular frequency, $\mathrm{A}$ is the amplitude and $\mathrm{P}$ is the sound pressure. Taking into account this equation, we can put the following expressions of the coefficients of reflection and transmission of sound pressure:

$$
\begin{aligned}
R^{\prime} & =\frac{P_{r}}{P_{i}} ; \\
T^{\prime} & =\frac{P_{t}}{P_{i}} ;
\end{aligned}
$$

in such a way that it can be put:

$$
\begin{aligned}
& R^{\prime}=\frac{P_{r}}{P i}=\sqrt{\frac{2 Z_{1} I_{r}}{2 Z_{1} I_{i}}}=\sqrt{R}=\frac{Z_{2}-Z_{1}}{Z_{2}+Z_{1}} \\
& T^{\prime}=\frac{P_{t}}{P i}=\sqrt{\frac{2 Z_{2} I_{t}}{2 Z_{1} I_{i}}}=\sqrt{T \frac{Z_{2}}{Z_{1}}}=\frac{2 Z_{2}}{Z_{2}+Z_{1}}
\end{aligned}
$$


From the expression 11 it is deduced firstly that the reflected acoustic pressure will be of the same amplitude, whatever the side of the limit surface on which the wave is incident, that is to say, independently of the sequence of both materials; although in the case of being $Z_{2}>Z_{1}, R^{\prime}$ will be positive, which indicates that the incident wave and the reflected wave are in phase and, in the opposite case $\left(\mathrm{Z}_{2}<\mathrm{Z}_{1}\right)$, $\mathrm{R}^{\prime}$ will be negative, which indicates an inversion of the phase of the reflected wave in relation to the incident wave.

From the expression 12 it is deduced that although the acoustic pressure transmitted in phase with the incident, it will not be independent of the sequence of the two materials, so that if $Z_{2}>Z_{1}$, then $T^{\prime}>1$, which indicates that its amplitude will be greater than that of the incident wave and, in the opposite case $\left(Z_{2}<Z_{1}, T^{\prime}<1\right)$ less.

Finally, the balance of sound pressure, in contrast to energy or sound intensity, can be put as

$$
\mathrm{P}_{\mathrm{i}}+\mathrm{P}_{\mathrm{r}}=\mathrm{P}_{\mathrm{t}} \text {, either } 1+\mathrm{R}^{\prime}=\mathrm{T}^{\prime}
$$

which implies that for balance to be maintained, the sum of the pressures must be the same on both sides of the interface.

\subsection{Methodology Applied to the Real Case}

The determination of possible defects in composite materials widely used in the industrial sector, is the problem to be addressed once established the theoretical foundations of the physical interaction of an ultrasonic wave with matter.

It is important that the use of these materials at a technological and industrial level guarantees that they do not have defects that reduce their mechanical properties considerably, especially in critical structures.

The main defects to be evaluated are:

- $\quad$ The punctual or generalized porosity that will be basically air inclusions within the polymeric matrix that could have been produced by a low pressure application in the resin curing process in its manufacturing process or by a movement between layers after the resin has started its molecular crosslinking process (Heru et al., 1997).

- In epoxy matrix carbon fiber laminates, low energy impacts cause damage that can result in dents, matrix cracking, fiber to matrix delamination and fiber breakage. Of all these, delamination is probably the most harmful due to the difficulty in detecting it and the reduction it causes in the properties (Baker; Jones \& Callinan, 1985; Wróbel, Wierzbicki \& Pawlak, 2005). The possible delaminations of a carbon fiber layer will be evaluated, these will be identified by the presence of air due to the detachment of successive layers of fiber due to lack of adhesion between them (Cantwell, Curtis, \& Morton, 1986; Miyano et al., 1994).

In Table 1, some physical and mechanical properties of some materials that will be used in the ultrasonic inspection process to be developed on the chosen composite material have been collected.

Table 1. Physical and mechanical data on some materials

\begin{tabular}{llll}
\hline Material & $\begin{array}{l}\text { Densidad } \\
\mathrm{P}(\mathrm{Kg} / \mathrm{m} 3)\end{array}$ & $\begin{array}{l}\text { Módulo elástico } \\
\mathrm{E}(\mathrm{Gpa})\end{array}$ & $\begin{array}{l}\text { Coeficiente de Poisson } \\
\text { (adimensional) }\end{array}$ \\
\cline { 2 - 4 } $\begin{array}{l}\text { Resina epoxy } \\
\text { Modificada 8552 }\end{array}$ & 3,4 & 0,4 \\
$\begin{array}{l}\text { Fibra de carbono (AS4 alta } \\
\text { resistencia) }\end{array}$ & 1790 & 330 & 0,1 \\
$\begin{array}{l}\text { Agua } \\
\text { Aire }\end{array}$ & 1000 & --- & --- \\
\hline
\end{tabular}

In the technical inspection performed by ultrasound we will find, first the water layer, since it is an inspection by immersion in water, then the polymer matrix formed by an epoxy resin type, the carbon fiber used as reinforcement, and finally, the presence of air in the form of porosity or delamination.

The speed of sound propagation in the different media $\left(\mathrm{C}_{\mathrm{L}}\right)$ and the acoustic impedance $(\mathrm{Z})$ will be determined, since the amount of reflected and transmitted sound will be obtained from these parameters. It will be taken into account that the speed of sound in air is $340 \mathrm{~m} / \mathrm{s}$ and in water $1435 \mathrm{~m} / \mathrm{s}$, and therefore, it is not necessary to calculate them. 


\subsubsection{Inspection for Porosities}

We are going to try to determine if it is possible to detect if there are air porosities in the manufactured composite material. We have already seen that one of the panels (P1) has been prepared expressly for this purpose and we have been able to determine them by means of immersion ultrasounds as shown in figure $2 \mathrm{~b}$. If there is porosity in the panel due to lack of pressure during the forming process, it will appear in the epoxy resin, so we must evaluate the combination of water, epoxy resin and air.

We will start the ultrasonic inspection study taking into account the water first (where the ultrasonic beam initially propagates). It will be taken into account that the inspection will be performed using a normal incidence probe with a frequency of $1 \mathrm{MHz}$ that will produce an intensity of $200 \mathrm{~dB}$.

The study will be carried out in two phases, that is, first the materials such as water and epoxy resin will be studied, and then, in a second phase, the epoxy resin will be studied with the air.

The following figure shows in schematic form the components of the materials to be taken into account to perform the ultrasonic inspection to locate the porosity in the material.

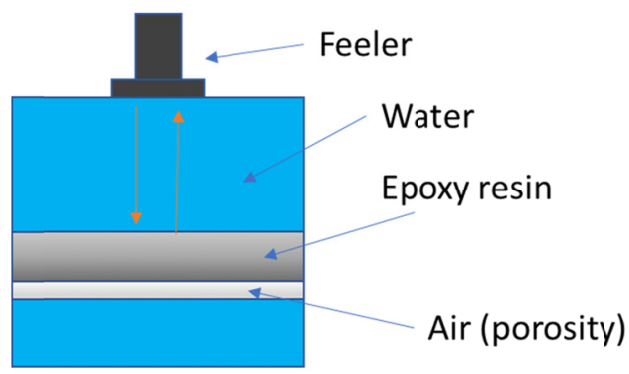

Figure 6. Distribution of layers in the study of porosity with perpendicular incidence of the acoustic wave on the flat surface of the plate

Phase 1: Water + epoxy resin

Using the formulas of the speed of sound propagation (1) and the acoustic impedance (2) and the parameters of Table 1 for the two materials that are analyzed in this phase, material 1 the water and material 2 the epoxy resin, the following results are reached:

Table 2. Acoustic velocity and impedance of water and epoxy resin

\begin{tabular}{lll}
\hline Material & Velocidad acústica & Impedancia acústica \\
& $\mathrm{C}_{\mathrm{L}}(\mathrm{m} / \mathrm{s})$ & $\mathrm{Z}\left(\mathrm{Kg} / \mathrm{m}^{2} . \mathrm{s}\right) * 10^{6}$ \\
\hline Agua & 1435 & 1,44 \\
Resina epoxy 8552 & 2573,59 & 2,83 \\
\hline
\end{tabular}

Using formulas 11 and 12 of the reflected and transmitted sound pressures respectively, we obtain the following results summarized in Table 3. In this case the water will be material 1 and the epoxy resin will be material 2 .

Table 3. Percentage of reflected and transmitted wave from water and epoxy resin

\begin{tabular}{lll}
\hline Material & $\begin{array}{l}\text { Reflectancia } \\
\mathrm{R}^{\prime}(\%)\end{array}$ & $\begin{array}{l}\text { Transmitancia } \\
\mathrm{T}^{\prime}(\%)\end{array}$ \\
\hline Agua & 32,55 & 132,55 \\
Resina epoxy 8552 & &
\end{tabular}

In this case, $Z_{2}>Z_{1}$ is positive, indicating that the incident and reflected waves are in phase. Being $Z_{2}>Z_{1}$, it indicates that $T^{\prime}>1$, which implies that the amplitude of the transmitted wave will be greater than that of the incident wave. The transmitted wave has an acoustic pressure of $132.55 \%$. This we will represent in figure 7. 


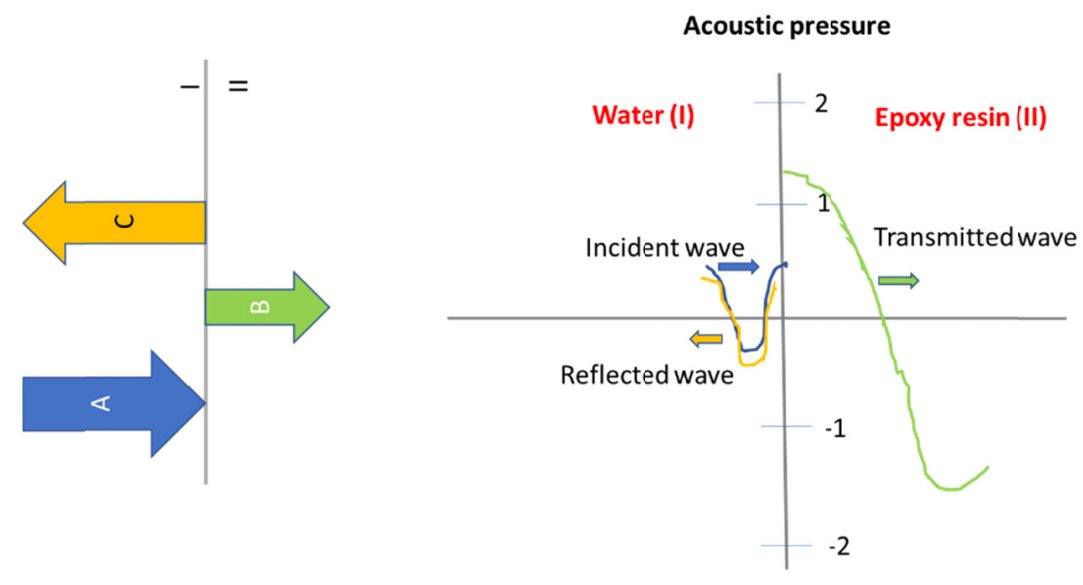

Figure 7. Acoustic pressures in the case of reflection in water and epoxy' resin

Figure 7 shows the values of the incident (blue) and reflected (orange) wave pressures in medium I (water). Also shown is the transmitted wave (green) in the epoxy resin matrix. The reflected and transmitted intensities will be the product of multiplying the incident power $(200 \mathrm{~dB})$ by the percentage of reflected $(32.55 \%)$ and transmitted wave $(132.55 \%)$ which gives intensities of $65.1 \mathrm{~dB}$ and $265.1 \mathrm{~dB}$ respectively.

Phase 2: Epoxy resin + air

For this study procedure, it will be operated in a similar way as in phase 1. If there is porosity in the panel due to lack of pressure during the forming process, it will appear in the epoxy resin, so we must evaluate the combination of epoxy resin with air, the first will be material 1 and air will be material 2 .

Table 4. Acoustic velocity and impedance for epoxy resin and air

\begin{tabular}{lll}
\hline Material & Velocidad acústica & Impedancia acústica \\
& $\mathrm{C}_{\mathrm{L}}(\mathrm{m} / \mathrm{s})$ & $\mathrm{Z}\left(\mathrm{Kg} / \mathrm{m}^{2} \cdot \mathrm{s}\right) * 10^{6}$ \\
\hline Resina epoxy 8552 & 2573,591435 & 2,83 \\
Aire & 340 & 0,00041
\end{tabular}

Using formulas 11 and 12 of the reflected and transmitted acoustic pressures respectively, we obtain the following results summarized in table 5 .

Table 5. Percentage of reflected and transmitted wave for epoxy resin and air

\begin{tabular}{lll}
\hline Material & Reflectancia & Transmitancia \\
& $\mathrm{R}^{\prime}(\%)$ & $\mathrm{T}^{\prime}(\%)$ \\
\hline Resina epoxy 8552 & $-99,97 \%$ & $0,028 \%$ \\
Aire & &
\end{tabular}

In this case of searching for porosity in the sample, it has been obtained that $Z_{2}<Z_{1}$, so that $R^{\prime}$ is negative, which indicates a phase inversion of the reflected wave with respect to the incident wave. $A s Z_{2}<Z_{1}$, it is also obtained that $T^{\prime}<1$ which implies that the transmitted wave is smaller than the incident wave. Figure 8 below will express graphically the results obtained. 


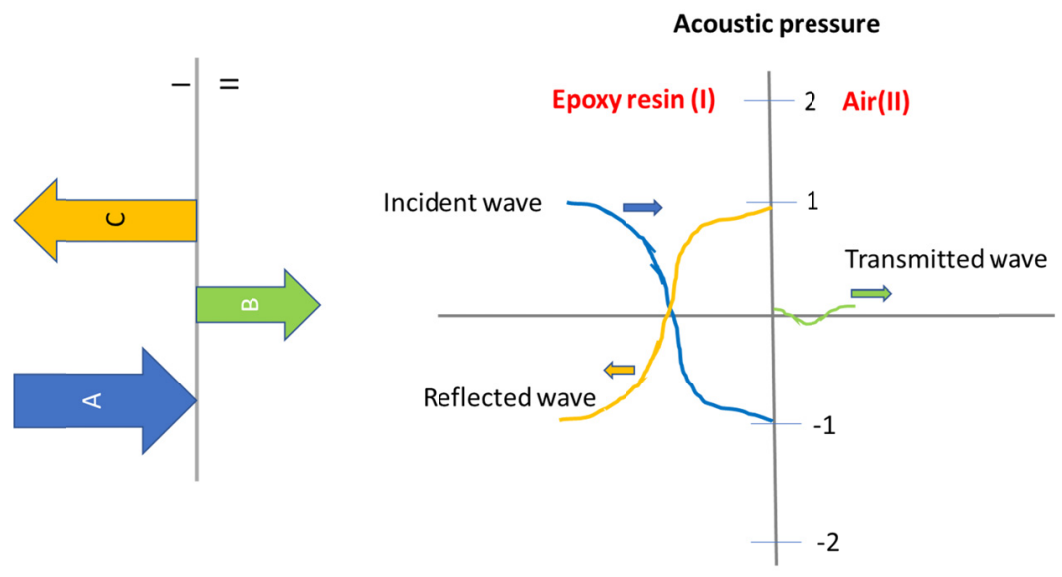

Figure 8. Acoustic pressures in the case of epoxy resin and porosity

Figure 8 shows the values of the pressures of the incident wave (blue) and reflected wave (orange) in the medium I (epoxy resin). It also shows the transmitted wave (green) in air (possible porosity). The reflected and transmitted intensities will be the product of multiplying the incident power $(200 \mathrm{~dB})$ by the percentage of reflected $(99.97 \%)$ and transmitted wave $(0.028 \%)$. To determine the intensities, it should be taken into account that the intensity of the incident wave is equal to the intensity of the wave transmitted in the previous phase, ie $265.1 \mathrm{~dB}$. Making this consideration, the reflected intensity will be $265.02 \mathrm{~dB}$ and the transmitted intensity will be $0.0742 \mathrm{~dB}$. The intensity of the transmitted wave is practically zero, however, the intensity of the reflected wave is practically the total (there is almost no attenuation), so that the porosity can be easily identified.

\subsubsection{Inspection for Delaminations}

If there is a delamination in the material, it will occur between layers of carbon fiber used as reinforcement, therefore, it will be taken into account that the ultrasonic beam will pass through the water layer, the polymer matrix, the carbon fiber and finally it will meet the delamination (if any) before passing through the next layer of carbon fiber. The scheme can be seen in the following figure 9.

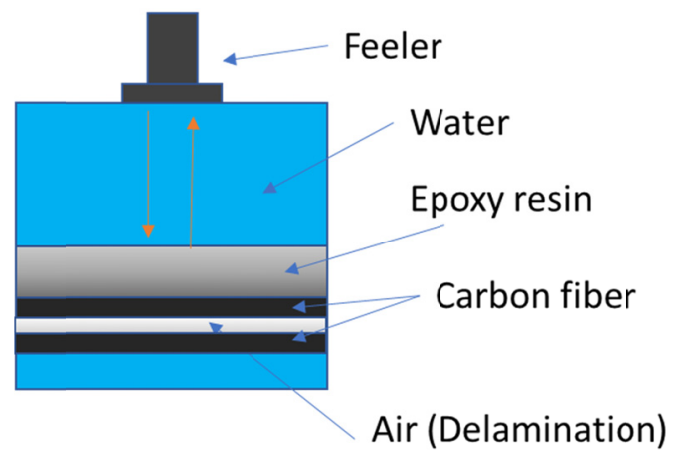

Figure 9. Distribution of layers in the study of delaminations with perpendicular incidence of the acoustic wave on the flat surface of the plate

For the study of delamination identification, it will be studied in three phases each with a set of two materials. For the first phase the water and epoxy matrix will be selected, for the second the epoxy matrix and the carbon fibre, and for the third and last one, the carbon fibre and the air (possible delamination). It is interesting above all that the quantity of wave that crosses the carbon fiber is the greater possible thing to be able to detect the later delamination.

Phase 1: Water + epoxy resin

The data obtained for the inspection for porosity will be valid for this phase, with a reflectance of $32.55 \%$ and a transmittance of $132.55 \%$, which translates into a reflected intensity of $65.1 \mathrm{~dB}$ and a transmitted intensity of 265.1 $\mathrm{dB}$. This value will be the one that in the study of the second phase enters as the incident wave value. 
Phase 2: Epoxy resin + carbon fiber

Taking into account equations 1 and 2, and the values of the analyzed materials referenced in Table 1, the speed and acoustic impedance of the two materials listed in Table 6 have been determined.

Table 6. Acoustic velocity and impedance for epoxy resin and carbon fiber

\begin{tabular}{lll}
\hline Material & Velocidad acústica & Impedancia acústica \\
& $\mathrm{C}_{\mathrm{L}}(\mathrm{m} / \mathrm{s})$ & $\mathrm{Z}\left(\mathrm{Kg} / \mathrm{m}^{2} \cdot \mathrm{s}\right) * 10^{6}$ \\
\hline Resina epoxy 8552 & 2573,591435 & 2,83 \\
Fibra de carbono AS4 & 13731,25 & 24,57
\end{tabular}

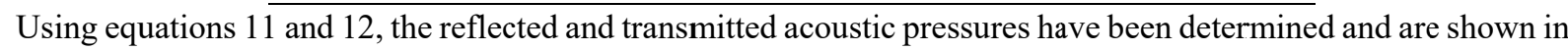
Table 7.

Table 7. Percentage of reflected and transmitted wave for epoxy resin and carbon fiber

\begin{tabular}{lll}
\hline Material & Reflectancia & Transmitancia \\
& R' $\left.^{\prime} \%\right)$ & T' $(\%)$ \\
\hline Resina epoxy 8552 & $79,34 \%$ & $179,34 \%$
\end{tabular}

Fibra de carbono AS4

In this case you have to $Z_{2}>Z_{1}$ so $R^{\prime}$ is positive, which indicates that the incident and reflected waves are in phase. Being $Z_{2}>Z_{1}$, it indicates that $T^{\prime}>1$, which implies that the amplitude of the transmitted wave will be greater than that of the incident wave. Because carbon fiber has a greater capacity to transmit sound, as indicated by the value of its impedance $\mathrm{Z}$, the transmitted wave will increase its power to $179.34 \%$. We are going to represent this in figure 10 .
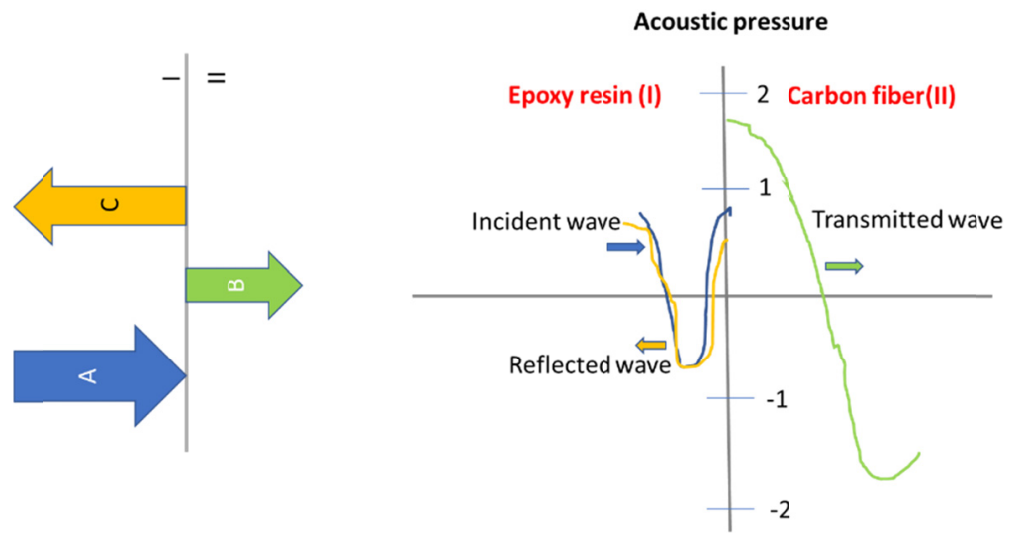

Figure 10. Acoustic pressures in the delamination study case for epoxy resin and carbon fiber

Figure 10 shows the values of the pressures of the incident wave (blue) and reflected wave (orange) in the medium I (epoxy resin). Also shown is the transmitted wave (green) in the carbon fiber. The reflected and transmitted intensities will be the product of multiplying the incident power $(265.1 \mathrm{~dB})$ by the percentage of reflected $(79.34 \%)$ and transmitted wave (179.34\%) which gives intensities of $210.33 \mathrm{~dB}$ and $475.43 \mathrm{~dB}$ respectively. This data is beneficial if what is sought is that the acoustic wave reaches the possible delamination.

Phase 3: Carbon fiber + air (delamination):

It remains to be studied how the acoustic wave would react when passing through the carbon fiber and reaching the possible delamination (presence of air). It should be noted again, that the incident wave is the one calculated as transmitted previously, that is, the one with an intensity of $475.43 \mathrm{~dB}$.

Table 8. Acoustic velocity and impedance of carbon fiber and possible delamination (air)

\begin{tabular}{lll}
\hline Material & Velocidad acústica & Impedancia acústica \\
& $\mathrm{C}_{\mathrm{L}}(\mathrm{m} / \mathrm{s})$ & $\mathrm{Z}\left(\mathrm{Kg} / \mathrm{m}^{2} \cdot \mathrm{s}\right) * 10^{6}$ \\
\hline Fibra de carbono AS4 & 13731,25 & 24,57 \\
Aire & 340 & 0,00041 \\
\hline
\end{tabular}


Table 9. Percentage of reflected and transmitted wave for carbon fiber and possible delamination

\begin{tabular}{lll}
\hline Material & $\begin{array}{l}\text { Reflectancia } \\
\text { R' }(\%)\end{array}$ & $\begin{array}{l}\text { Transmitancia } \\
\text { T' }(\%)\end{array}$ \\
\hline Fibra de carbono AS4 & $-99,99 \%$ & $0,0033 \%$ \\
Aire & & \\
\hline
\end{tabular}

In this case of searching for delaminations in the sample, it has been obtained that $\mathrm{Z}_{2}<\mathrm{Z}_{\mathbb{1}}$, so that $\mathrm{R}^{\prime}$ is negative, which indicates a phase inversion of the reflected wave with respect to the incident wave. As $Z_{2}<Z_{1}$, it is also obtained that $\mathrm{T}^{\prime}<1$ which implies that the transmitted wave is smaller than the incident wave. Figure 11 will express graphically the results obtained.

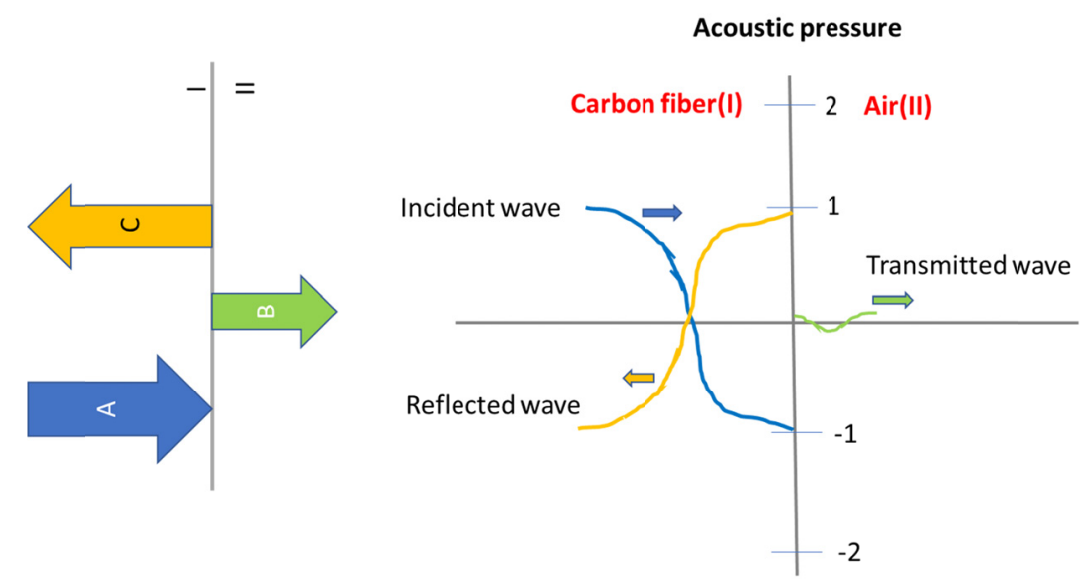

Figure 11. Acoustic pressures in the delamination study case for carbon fiber and delamination

Figure 11 shows the values of the pressures of the incident wave (blue color) and reflected wave (orange) in the medium I carbon fiber). The transmitted wave (green) is also shown in the possible delamination. The reflected and transmitted intensities will be the product of multiplying the incident power $(475.43 \mathrm{~dB})$ by the percentage of reflected $(99.99 \%)$ and transmitted wave $(0.0033 \%)$ which gives intensities of $475.38 \mathrm{~dB}$ and $0.0156 \mathrm{~dB}$ respectively. The reflected intensity is practically the same as the one that has come from the carbon fiber layer, however, the transmitted one is very small. Therefore, $0.0033 \%$ of the $\mathrm{dB}$ will be transmitted, so the detector must identify a signal of $0.0156 \mathrm{~dB}$ that would be a quite low signal. Probably, it would not be possible to identify a delamination in this type of samples with the signal used of $1 \mathrm{MHz}$ frequency and $200 \mathrm{~dB}$ intensity, since the attenuation of the signal that had been emitted is practically total. Therefore, in order to identify this type of defect, it should be considered to work with higher frequencies and sound intensities.

\section{Results}

This study of defect identification in composite materials has shown how porosities and delaminations can be identified in this type of material using the technique of ultrasound immersion.

Ultrasounds, as a NDT technique, has a high penetration power because in the test provides information of the entire volume of the sample but with the ability to test greater thicknesses, has a high sensitivity which allows the detection of very small defects (depending on the quality of the material analyzed), the position of internal defects is accurately determined, as well as the estimation of size, orientation, shape and nature of heterogeneity, only need access by a surface to perform the test, the result of the inspection is instantaneous (real time) since the whole process of signal generation and reception is controlled electronically, the technique of image capture of the test makes possible an adequate documentation of it, there are no risks for the operator or for the people who could be observing the test, they have a high versatility since the ultrasound test has a great amount of resources that allow to undertake a great amount of industrial problems (Miyano et al., 1986; Wan et al., 2016). They also have some disadvantages, such as requiring highly qualified personnel, small, irregular, rough or thin samples are complicated to inspect, the passage of acoustic energy from the probe to the sample and viceversa requires the use of a coupling fluid, heterogeneities very close to the surface may not be detected and the calibration of the test system and the determination of certain characteristics of the defects requires the use of standard or reference samples. 
Calculations of the percentages of acoustic intensities of reflected and transmitted waves allow more or less easily to determine if it is possible to detect defects (porosity and delaminations) in a material (composite). It will be taken into account that for the inspection of delaminations, an almost complete attenuation of the transmitted wave is produced, so in practice, for the search of this type of defects, it should be taken into account to work with higher frequencies, as well as acoustic intensities.

\section{Discussion}

Unidirectional components are not commonly used in aerospace structural components due to their high anisotropy of mechanical properties. Normally multidirectional laminates are used which are optimal for different load conditions (Miyano et al,,1986; Marsh, 2002; DobrzaÉski, 2002). Even so, it is necessary to study unidirectional laminates since this allows us to know how the material behaves in the direction of the fibers, since the sheet presents maximum properties in this direction and minimum properties in the transversal direction. The tested laminate presents the highest resistance and elastic module and the lowest possible thermal expansion coefficient in one direction.

The study of the use of the physical phenomena of interaction of the ultrasonic wave in the composite material is an excellent tool to identify defects by ultrasound in this type of materials. This will help the beginners who are initiated in the application of this type of methodologies (especially the ultrasounds) in the laboratories to be able to adjust in a theoretical way the measurement devices, one of the most pronounced difficulties in this type of measurements. This will also provide an approximate idea of the frequency and intensity of work for certain types of materials and defects, reducing preparation times and costs of testing.

\section{Acknowledgements}

The authors wish to thank CEU San Pablo University Foundation for the funds dedicated to the Project Ref. USP CEU-CP20V12 provided by CEU San Pablo University.

\section{References}

Alonso, M., \& Finn, E. (1987). Física. Vol II (Campos y Ondas). Ed. Addison Wesley, Iberoamericana, Wilmington.

ASM International Handbook Committee. (1989). Engineered Materials Handbook, 1, Composites.

Baker, A. A., Jones, R., \& Callinan, R. J. (1985). Damage tolerance od graphite/epoxy composites. Composite Structures, 4(1), 15-44. https://doi.org/10.1016/0263-8223(85)90018-2

Barbero, E. J. (1999). Introduce to Composite Materials Design. Taylord \& Francis, Inc.

Bishop, S. M. (1985). The mechanical performance and impact behavior of carbon fibre reinforced PEEK. Composite Structures, 3, 295-318. https://doi.org/10.1016/0263-8223(85)90059-5

Cantwell, W. J., Curtis, P., \& Morton, J. (1986). An assesment of the impact performance of CERP reinforced with high-strain carbon fibres. Composite Science Technology, 25(2), 133-148. https://doi.org/10.1016/0266-3538(86)90039-4

DobrzaĚski, L. A. (2002). Fundamentals of Materials Science and Physical Metallurgy. WNT, Warszawa (in Polish).

Dunegan, H. L., \& Tetelman. (1971). Acoustic Emission. Research and Development, 22(5), 20-24.

Gray, S., Ganchev, S., Qaddoumi, N., Beauregard, G., \& Radford, D. (1995). Porosity level estimation in polymerer composites using microwaves. Applied Microwave Nondestructive Testing laboratory, Electrical Engineering Department, Colorado State University, Ft. Collins. Material Evaluation, 404-408.

Harvey, A. (1963). Microwave Engineering. Academic Press.

Heru, S. B., Komotori, J., Shimizu, M., \& Miyano, Y. (1997). Effects of the fiber content on the longitudinal tensile fracture behavior of uni-directional carbon/epoxy composites. Journal of Materials Processing Technology, 67, 89-93. https://doi.org/10.1016/S0924-0136(96)02824-5

Hervfeld, K. F., \& Litovitis, T. A. (1959). Absorption and Dispersion of Ultrasonic Waves, 535.

Huang, Y. D., Liu, L., Zhang, Z. Q., \& Wan, Y. (1998). On-line monitoring of resin content for film impregnation process. Composites Science and Technology, 58, 1531-1534. https://doi.org/10.1016/S0266-3538(97)00185-1 
Huang, Y. D., Liu, L., Qui, J. H., \& Shao, L. (2002). Influence of ultrasonic tretment on the characteristics of epoxy resin and the interfacial property of its carbon fiber composites. Composites Science and Technology, 62(16), 2153-2159. https://doi.org/10.1016/S0266-3538(02)00148-3

ImieliĚska, K., Castaings, M., Wojtyra, R., Haras, J., Le Clezio, E., \& Hosten, B. (2004). Air-coupled ultrasonic $\mathrm{C}$-scan technique in impact response testing of carbon fibre and hybrid: glass, carbon and Kevlar/epoxy composites. Journal of Materials Processing Technology, 157-158, 513-522. https://doi.org/10.1016/j.jmatprotec.2004.07.143

INASMET. (1998). Materiales compuestos. Tecnologías de producción. Centro tecnológico de materiales Inasmet, San Sebastián, España.

Kapranos, P., \& Priestner, R. (1987). NDE of difusión bonds. Metals and Materials, 194-198.

KINO, G. S. (1979). Acoustic imaging for nondestructive evaluation. IEEE, 67(4), 510-525. https://doi.org/10.1109/PROC.1979.11280

Marsh, G. (2002). Finding flaws in composites. Reinforced Plastics, 46(12), 22-28. https://doi.org/10.1016/S0034-3617(02)80227-2

Maslov, K., Kim, Y. R., Kinra, K. V., \& Pagano, J. N. (2000). A new technique for the ultrasonic detection of internal transverse cracks in carbon-fibre/bismaleimide composite laminates. Composite Science and Technology, 60, 2185-2190. https://doi.org/10.1016/S0266-3538(00)00013-0

Miyano, Y., Kanemitsu, M., Kunio, T., \& Kuhn, H. A. (1986). Role of matrix on fracture strengths of unidirectional CFRP. Journal of Composite Materials, 20, 520-538. https://doi.org/10.1177/002199838602000602

Miyano, Y., McMurray, M. K., Kitade, N., Nakada, M., \& Mohri, M. (1994). Role of matrix resino n the flexure static behavior of unidirectional pitch-based carbon fiber laminates. Advanced Composite Materials, 4(2), 87-99. https://doi.org/10.1163/156855194X00222

Mouritz, A. P., Townsend, C., \& Shah Khan, M. Z. (2000). Nondestructive detection of fatigue damage in thick composites by pulse-echo ultrasonics. Composites Science and Technology, 60, 23-32. https://doi.org/10.1016/S0266-3538(99)00094-9

Mundry, E. (1968). Ultrasonidos. Trad. Ed. 1961. INTI. Argentina, 124.

Nesvijski, G. (2000). Some aspects of ultrasonic testing of composites. Composite Structures, 48, 151-155. https://doi.org/10.1016/S0263-8223(99)00088-4

Ochelski, S. (2004). Experimental methods in construction composites mechanics. WNT, Warszawa (in Polish).

Padmanabhan, K., \& Kishore, E. (1995). Failure behaviour of carbon fibre/epoxy composites in pìn-ended buckling and vending test. Composites, 26(3), 201-206. https://doi.org/10.1016/0010-4361(95)91383-G

Pollock, A. A. (1987). Acoustic Emission Inspection. Metals Handbook, 17. Non Destructive Evaluation and Quality Contro, 278-294.

Potel, C., Chotard, T., Belleval, J. F., \& Benzeggagh, M. (1998). Characterization of composite material by ultrasonic methods. Composites Part B, 159-169. https://doi.org/10.1016/S1359-8368(97)00006-1

Rámirez López, Fc., Del Ojo, G., Fernández Soler, M. A., Valdecantos, C., Alonso, A., \& De los Ríos, J. M. (1996). Métodos de Ensayos No Destructivos. Instituto de Técnica Aeroespacial (INTA).

Ramírez, F., \& Col. A. (1982). Introducción a los métodos de ensayos no destructivos de control de calidad de los materiales, $3^{\mathrm{a}}$ edición, INTA, Madrid, Spain.

Richardson, E. G. (1952). Ultrasonic Physics. Elsevier Publishing Companu, Amsterdam, London, New York. https://doi.org/10.1063/1.3067396

Rojek, M., Stabik, J., \& Wróbel, G. (2005). Ultrasonic methods in diagnostics of epoxy-glass composites. Journal of Materials Processing Technology, 162-163. https://doi.org/10.1016/j.jmatprotec.2005.02.069

Sanglier, G., Del Ojo, G., De Miguel, J., \& Peñaranda, J. A. (2003). Estudio mediante Ensayos No Destructivos de la cubierta ("Radomo") de un sistema experimental de radar de apertura sintética. $10^{\circ}$ Congreso Nacional de E.N.D. Asociación Española de Ensayos No Destructivos. Cartagena, España. 
Scarponi, C., \& Briotti, G. (2000). Ultrasonic technique for the evaluation of delamination on CFRP, GFRP, KFRP composite materials. Composites, Part $B$ 31, 237-243. https://doi.org/10.1016/S1359-8368(99)00076-1

Silk, M. G. (1982). Defect detection and sizing in metals using ultrasound. International Metal Rev., 1, 28-50. https://doi.org/10.1179/imr.1982.27.1.28

Vaccaro, C., \& Akers, D. (1996). Damage assesment in a SMC composite by means of ultrasonic techniques. Review of Progress in Quantitative Nondestructive Evaluation, 13. Plenum Press, New York.

Valdecantos, C., Miguel, J., \& Gallego, E. (1995). Ensayo por ultrasonidos de materiales compuestos. Técnicas de impulso eco. $5^{\circ}$ Congreso español de técnicas END. Sevilla, Spain.

Wan, H., Ning, F., Hu, Y., Fernando, PKSC, \& Pei, Z. J. (2016). Surface grinding of carbon fiber-reinforced plastic composites using rotatory ultrasonic machining: Effects of tool variables. Advanced in Mechanical Engineering, 8(9), 1-14. https://doi.org/10.1177/1687814016670284

Wróbel, G., \& Wierzbicki, A'. (2005). Ultrasounds in diagnosis of strength changes in laminates put in agening conditions. 3rd Scientific Conference on Materials, Mechanical and Manufacturing Engineering, 575-580.

Wróbel, G., Wierzbicki, A'., \& Pawlak, S. (2005). Ultrasonic quality evaluation method for polyester glass laminated materials. 11th International Scientific Conference on Contemporary Achievements in Mechanics, Manufacturing and Materials Science. Gliwice - Zakopane, 1040-1044.

\section{Copyrights}

Copyright for this article is retained by the author(s), with first publication rights granted to the journal.

This is an open-access article distributed under the terms and conditions of the Creative Commons Attribution license (http://creativecommons.org/licenses/by/4.0/). 